\title{
EDITORIAL
}

\section{The 33rd international symposium on pediatric surgical research}

\author{
Prem Puri $^{1}$
}

Published online: 19 January 2021

(c) The Author(s), under exclusive licence to Springer-Verlag GmbH, DE part of Springer Nature 2021

On behalf of the Scientific Committee of the International Board of Pediatric Surgical Research:

Due to the ongoing global Covid-19 pandemic and resulting travel restrictions, the 33rd International Symposium on Pediatric Surgical Research (ISPSR) was held online from Frankfurt, Germany from 12 to 13 December 2020. This was a highly successful virtual meeting at which 50 papers on pediatric surgical research and 4 invited lectures were presented. As always, the highlight of the symposium was the Prize Session. There were ten excellent papers presented at this session. The Prem Puri Basic Science Research Prize was awarded to Dr. Joshua O' Connell from Toronto,
Canada, for his presentation on "Administration of Extracellular Vesicles Derived from Human Amniotic Fluid Stem Cells: A New Treatment For Necrotizing Enterocolitis".

The International Board of Pediatric Surgical Research thanks Professor Udo Rolle, Dr. Florian Friedmacher and the entire Frankfurt team for a highly successful virtual meeting.

Publisher's Note Springer Nature remains neutral with regard to jurisdictional claims in published maps and institutional affiliations.

Prem Puri

prof.prempuri@gmail.com

1 Beacon Hospital, University College Dublin, Dublin, Ireland 